\title{
Laser Machining For Fabrication Of Hohlraums And Capsules
}

M. D. Shirk, B. T. Kelly, S. M. Haynes, B. C. Stuart, J. J. Sanchez, J. D. Moody, R. C. Cook

July 8,2005

The Fusion Science And Technology 
This document was prepared as an account of work sponsored by an agency of the United States Government. Neither the United States Government nor the University of California nor any of their employees, makes any warranty, express or implied, or assumes any legal liability or responsibility for the accuracy, completeness, or usefulness of any information, apparatus, product, or process disclosed, or represents that its use would not infringe privately owned rights. Reference herein to any specific commercial product, process, or service by trade name, trademark, manufacturer, or otherwise, does not necessarily constitute or imply its endorsement, recommendation, or favoring by the United States Government or the University of California. The views and opinions of authors expressed herein do not necessarily state or reflect those of the United States Government or the University of California, and shall not be used for advertising or product endorsement purposes. 


\title{
Laser Machining for Fabrication of Hohlraums and Capsules
}

\author{
M. D. Shirk, B. T. Kelly, S. M. Haynes, B. C. Stuart, J. J. Sanchez, J. D. Moody, \\ R. C. Cook, Lawrence-Livermore National Laboratory, Livermore, CA 94550
}

This work was performed under the auspices of the U.S. Department of Energy by the University of California, Lawrence Livermore National Laboratory under contract No. W-7405-Eng-48.

\section{Abstract}

Laser machining technology has been used to demonstrate the ability to rapidly perform jobs on all aspects of ICF targets. Lasers are able to rapidly perform modifications and repairs to the gold metal parts on hohlraums, make cuts in the delicate polymer parts of the hohlraum, and drill holes in the capsules to enable them to be filled with fuel. Lasers investigated in this work include 193 $\mathrm{nm}$ ArF and $248 \mathrm{~nm} \mathrm{KrF}$ excimers and $810 \mathrm{~nm}$ chirped-pulse amplification Ti:Sapphire lasers. The excimer lasers showed a definite advantage in drilling and machining of polymeric materials and the ultrashort infrared pulses of the Ti:Sapphire laser were far better for the gold structures.

\section{Introduction}

Lasers offer some unique abilities to the $R \& D$ environment of a fusion program that no other technology can provide. In this work some of the abilities

of excimer and ultrashort pulsed lasers are presented. Excimer lasers have been used to modify gold hohlraums and to drill small holes in polymer capsules and make precision cuts in the formvar tents. They have also been used to cut polyimide fill tubes.

The nanosecond pulses of the excimer laser uses different material removal mechanisms depending on the material. In polymeric materials the laser 
uses a process called photoablation [1]. This process relies on the high intensity ultraviolet light to attack the covalent bonds in the material and this yields a very clean and precise material removal process. In metals (and semiconductors), the materials are much more refractory and the bonding is metallic in nature. Here the ultraviolet light is absorbed linearly by the conduction band electrons, the material then melts and boils. Much of the material removal is perform by vaporization or a mixture of that and melt ejection [2]. This leads to a process

that has large heat affected zones, remelted material and dross. A new class of lasers has been developed in the last 10 years or so that uses ultrashort pulses of around $100-f s$ in length. This works very well on metals without heat affected zones and redeposited material [3].

This work shows a comparison between using an excimer as a one laser solution for all aspects of target fabrication, and how the addition of an ultrashort pulsed laser can enhance the machining of the metallic parts.

\section{Experimental Method}

An LPX 325i made by Lambda Physik was used for the excimer laser investigation in this work. It can be operated at multiple wavelengths by simply switching out some optics and changing the chemical makeup of the gases used in it. For $193 \mathrm{~nm}$ light, a mixture of argon and fluorine are added to the buffer gases (helium and neon). The same laser can have its optics switched and Krypton can be substituted for the argon, yielding $248 \mathrm{~nm}$ photons. The main advantage of the $\mathrm{KrF}$ configuration is that power output of the laser is increased by approximately a factor of two. For this work both mask image projection [4] and single point cutting (using a circular mask) were investigated to create 
features of desired shapes, a comparison is shown in Figure 1a and 1b. For machining of features onto the cylindrical side of the hohlraum, it was determined that the depth of focus was not adequate to do mask image projection, so we performed single point cutting and used the motion system to keep the part in focus throughout the cut. This is the least efficient method of operation for an excimer since most of the laser energy is stopped at the mask. We also used an ultrashort pulsed (100-fs, $810-\mathrm{nm}$ ) CPA Ti:Sapphire laser to machine slots into gold, and to repair hohlraums where the laser entrance hole was not properly cut before the mandrel was leached out. The laser specifications are $810-\mathrm{nm}, 100$-fs pulsewidth, $3.5 \mathrm{kHz}$ pulse repetition rate, and an average power maximum of 0.5 W. This system used a focused Gaussian beam to perform machining and drilling, as shown in Figure 2. Polymer samples were characterized in optical and scanning electron microscopes, for the SEM images the samples were coated with a thin layer of palladium.

\section{Results and Discussion}

\section{Hohlraum modifications}

Features and cuts were made on gold hohlraums (various General Atomics parts) and on 1 inch square copper square coupons that were electrodeposited with 50 _m thick gold coatings. Figure 3 shows a starburst pattern cut into the side of a hohlraum that was still on its copper mandrel with an ArF excimer laser. A $1.5 \mathrm{~mm}$ diameter round aperture was demagnified onto the part at a ratio of 25:1 using a $50 \mathrm{~mm}$ microscope objective, Optics for Research, Inc. LMU-3X-193. The laser took three passes at a feed rate of $0.02 \mathrm{~mm} / \mathrm{s}$ to cut these slots with the laser set at $200 \mathrm{~mJ} /$ pulse and a $2 \mathrm{X}$ beam expanding 
telescope before the mask. A light purge of argon was used to shield the surface. The surface was cleaned with ethanol and a cotton swab before leaching in nitric acid. It still had a slight amount of recast material. The cutting rate is so slow because the repetition rate of the laser is relatively low. If the samples were flat, or if proper optics were used to compensate for the large zaxis changes due to the curvature of the part, then cutting speeds would be greater and quality may be improved some.

The ultrashort pulsed laser was later used to perform similar work on the surrogate flat coupons and on the laser entrance hole of a hohlraum that wasn't properly machined. Both showed excellent results. Figure 4 shows pictures of the slots cut into the as-deposited gold on the copper coupon and Figure 5 shows the results of cutting out the laser entrance hole on the leached out hohlraum. These were cut with the laser operating at $75 \mathrm{~mW}$ using a $60 \mathrm{~mm}$ graded refractive index lens. Ultrashort pulsed lasers cut cleaner and faster because of a combination of the improved physics of ablation over longer pulsed lasers [5] and because of the high repetition rate, $3.5 \mathrm{kHz}$ versus $200 \mathrm{~Hz}$.

\section{Capsule Drilling}

Plastic capsule surrogate materials were drilled using the excimer laser. Both $193 \mathrm{~nm}$ and $248 \mathrm{~nm}$ give excellent results drilling plastics. The goal of this work was to drill 5 _m or smaller diameter holes in $\mathrm{CH}$ plasma polymer. We chose Kapton and Upilex as surrogate materials because they are spectrally similar to the plasma polymer material. To perform this work we used a small aperture that was laser cut in a stainless steel foil. The best results were achieved with the 250 _m aperture in the beam and we used an Optics for 
Research, Inc. LMU-15X-248 ultraviolet focusing achromatic objective, effective focal length is $13 \mathrm{~mm}$ and the numerical aperture is 0.32 . The demagnification used was $37: 1$. Since the depth of focus is so small in this setup, a line of holes was drilled in the material changing the z-position by 0.5 _m between shots and drilling a hole. The holes were then observed using scanning electron microscopy. Figure 6 shows several SEM images of a hole drilled in $150 \_\mathrm{m}$ thick Upilex. These are very clean and straight holes, with a small amount of taper, some of which is due to the beam intensity distribution of the excimer laser, in the major axis it is pseudo top-hat, in the minor axis it is Gaussian. The holes get larger and rapidly rougher if the distance from the optical focal plane is greater than $1 \_\mathrm{m}$ or so. Therefore an optical setup will be needed to place the capsule so that the surface to be drilled is within the $1 \_\mathrm{m}$ zone needed to get proper hole quality. Larger and smaller holes can also be created accurately by switching out the mask. This technique will be used to make the counter-bores to hold the fill tube.

\section{Plastic Part Machining}

The tenting material in the hohlraum is made from a polymeric material called Form-var. It is approximately $80 \mathrm{~nm}$ thick, and must be cut so that it doesn't stretch in a non-uniform manner because this will prevent the capsule from being properly centered in the hohlraum. The excimer was able to cut this material quite readily at $248 \mathrm{~nm}$. The laser was set up using a LMU-5X-248 objective and the $250 \_\mathrm{m}$ aperture. The laser was set to run at $100 \mathrm{~Hz}$ and 13.0 $\mathrm{KV}$ ( the lowest voltage setting) and a 2:1 beam expanding telescope was also used before the aperture to reduce the intensity. The material was then mounted 
on the rim of the hohlraum half and circular arcs were cut into the material. The gold was not damaged at all, and the tenting material was cut precisely. Cuts in test material are shown in Figure 7, which demonstrates how smoothly and cleanly these materials can be cut. Figure 8 shows a picture of a film mounted on a gold hohlraum.

The other plastic parts that were trimmed are double-walled polyimide fill tubes. Lasers are one of the few means to trim these tubes so that no burr or other problems occur that would interfere with their insertion into the counter bore of a fill hole. In this instance we used $193 \mathrm{~nm}$ light, focused using a $50 \mathrm{~mm}$ lens. The laser illuminated a 250 micron wide slide which was then demagnified at approximately 9.5:1 onto the tube. 36 pulses were delivered at $120 \mathrm{~Hz}$. Two samples of the tubes that were cut are shown in Figure 9. These tips are burr free.

\section{Conclusion}

The use of lasers as a tool for rapid modification of fusion targets has been presented. An excimer as a one laser solution may be adequate, but adding an ultrashort pulsed system to the list greatly improves quality and speed in metal parts. Ultrashort pulsed lasers were also shown to be able to rapidly make repairs to expensive parts such as hohlraums even after the copper mandrel has been removed.

\section{References}

1. V. Mayne-Banton and R. Srinivasan, Applied Physics Letters 41 (6), 576-8 (1982) 
2. J. F. Ready, Ed. 2001 Handbook of Laser Materials Processing, Magnolia Publishing, Inc, Orlando FI. p 426.

3. P. P. Pronko, S. K. Dutta, J. Squier, J. V. Rudd, D. Du, and G. Mourou, Opt. Commun. 114, 106 (1995).

4. J. F. Ready, Ed. 2001 Handbook of Laser Materials Processing, Magnolia Publishing, Inc, Orlando FI. p 491.

5. C. Momma et al, Appl Surf Scie 109/110 (1997) 15-19.

\section{Figure Captions}

Figure 1. Left shows how an excimer laser works using mask-image projection to make desired features on a part all at once. Right shows how an excimer may be used as a single point cutting tool.

Figure 2. A CPA Ti:Sapphire laser was used to perform machining on gold coated copper coupons and on gold hohlraums that have already been leached. The system incorporates a 3 axis motion system that is computer controlled to position and move the part and control the laser shutter.

Figure 3. This is a microscope image of a hohlraum that had a diagnostic feature machined into it using an excimer laser. An identical feature was placed on the opposite side of the hohlraum so that optical and $\mathrm{x}$-ray diagnostics methods can be tested and investigated that need to pass through the hohlraum.

Figure 4. Slots were cut into gold deposited on copper to show the improved quality available from using ultrashort laser cutting.

Figure 5. Ultrashort pulsed CPA Ti:Sapphire laser was used to cut the laser entrance hole from a hohlraum that was not completely machined before it 
was leached from its copper mandrel.

Figure 6. This is a hole drilled with a $248 \mathrm{~nm} \mathrm{KrF} \mathrm{excimer} \mathrm{laser} \mathrm{through}$ 150 m thick upilex films as a surrogate to capsule materials. There is very little taper and the walls of the hole are quite smooth. Figure $6 \mathrm{a}$ is the entrance, Figure $6 b$ is the exit.

Figure 7. This is $80 \mathrm{~nm}$ thick formvar that is used as tenting material to hold the capsule in the center of the hohlraum. It was laser cut with the excimer and shows excellent precision.

Figure 8. This is a formvar film cut on a gold hohlraum. We show that not only can the excimer precisely cut the formvar, it can do so without marring the gold mating surface of the hohlraum.

Figure 9. Two polyimide tubes that were laser cut using the excimer are shown. Tradition mechanical cutting methods cause too much burr or crushing of the tube to allow the tube to be inserted into the capsule and still be capable of flowing the DT fuel mixture.

\section{Figure graphics}

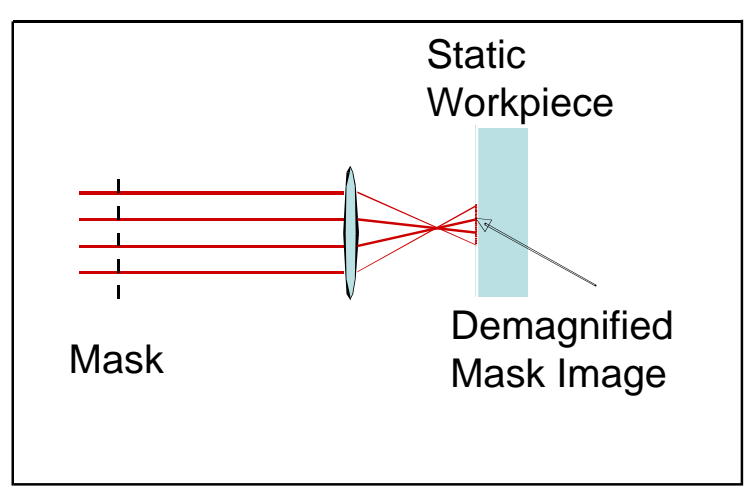

Figure 1.a 


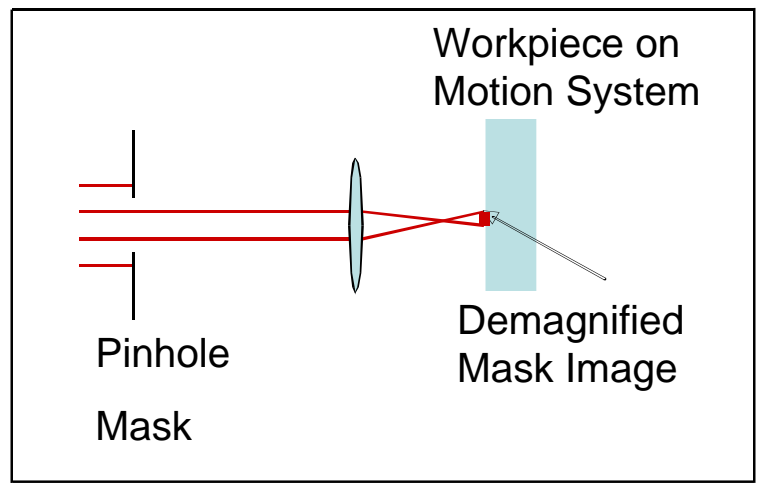

Figure $1 b$.

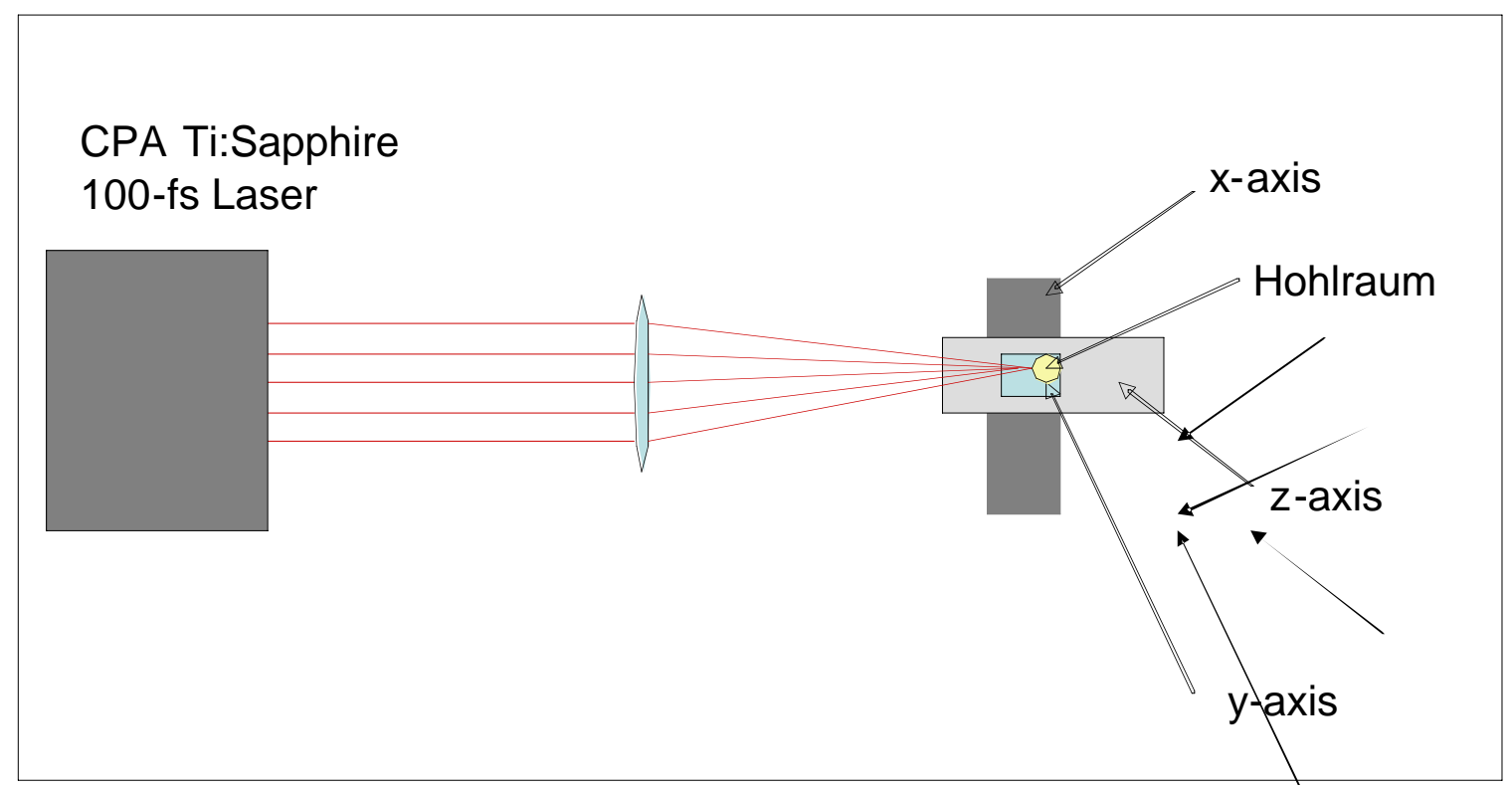

Figure 2. 


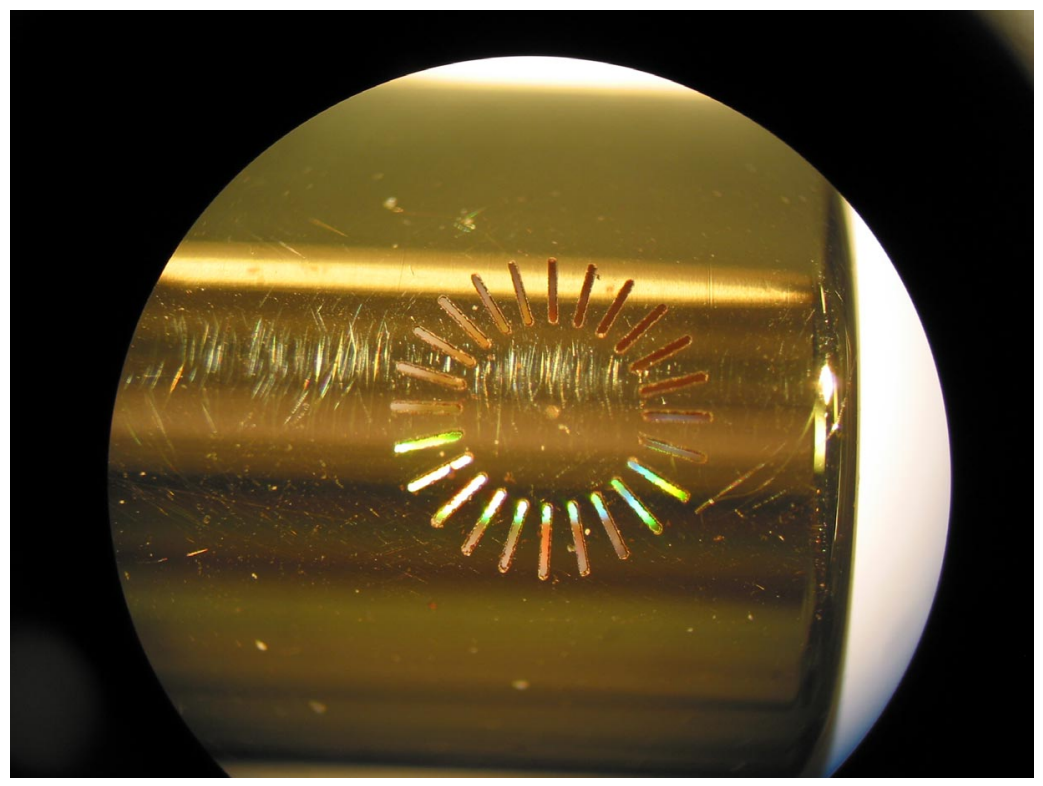

Figure 3 .

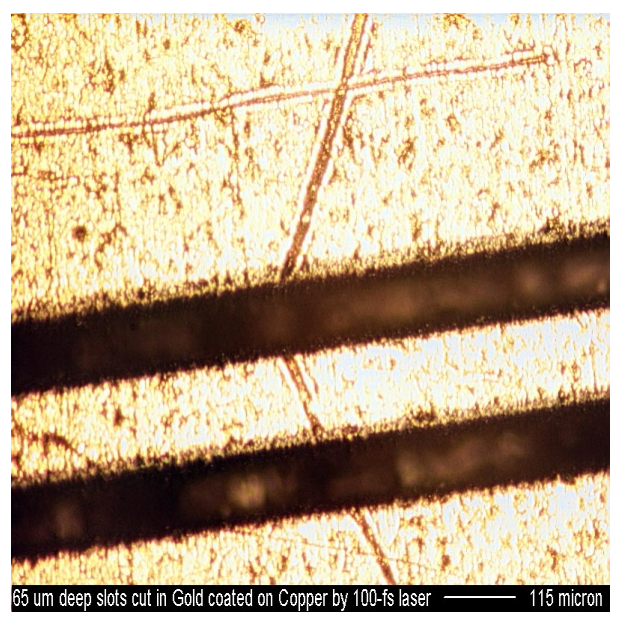

Figure 4. 


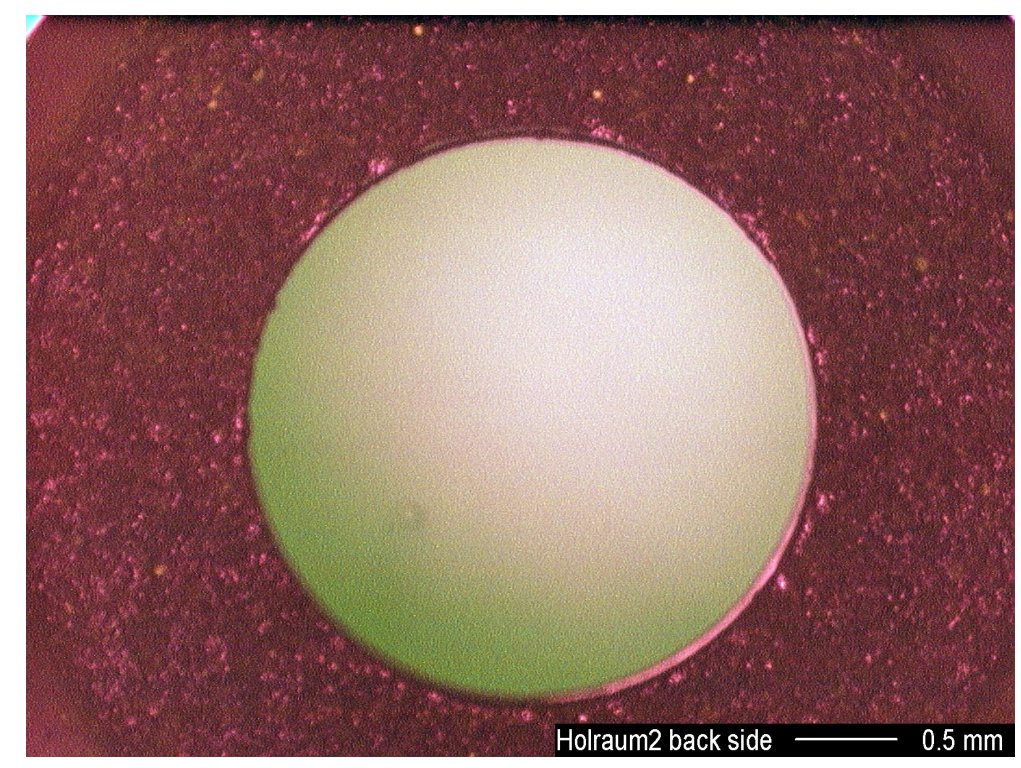

Figure 5.
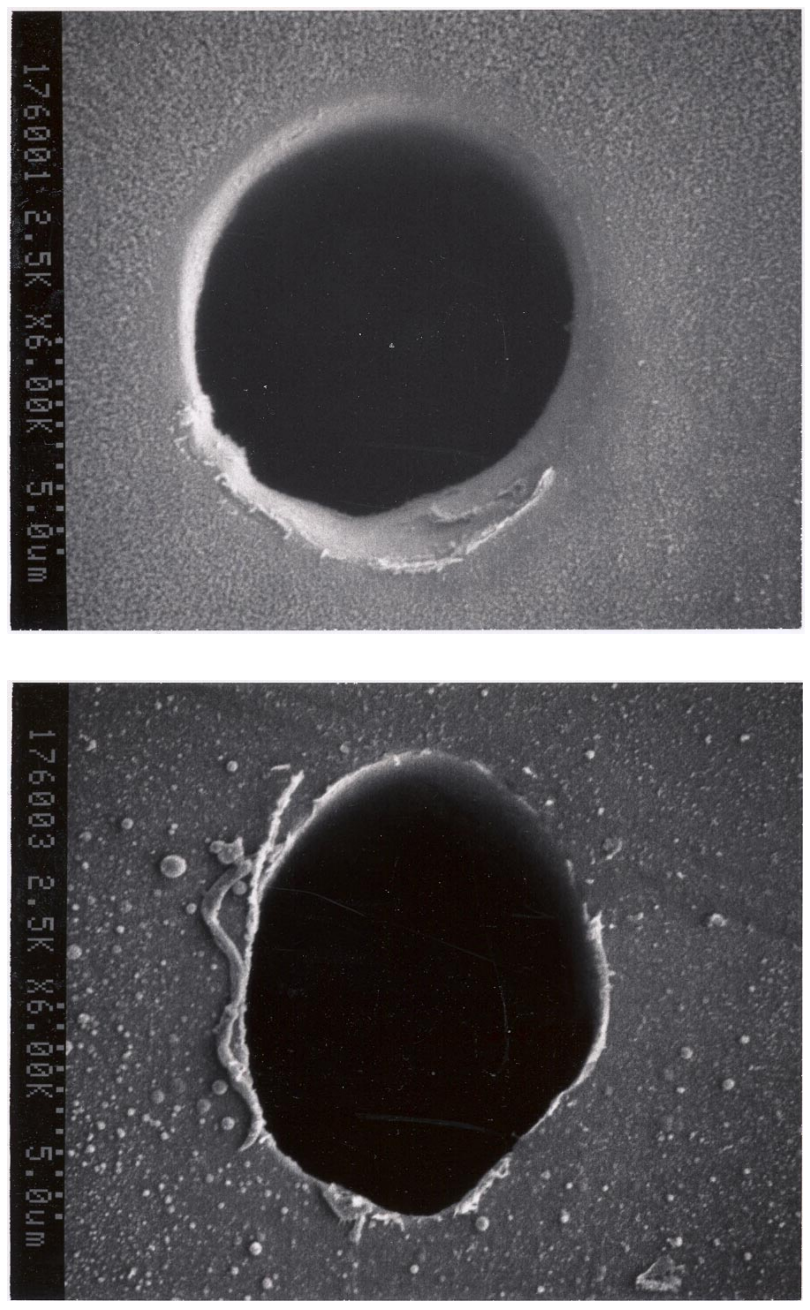
Figure 6b. Small hole in Kapton

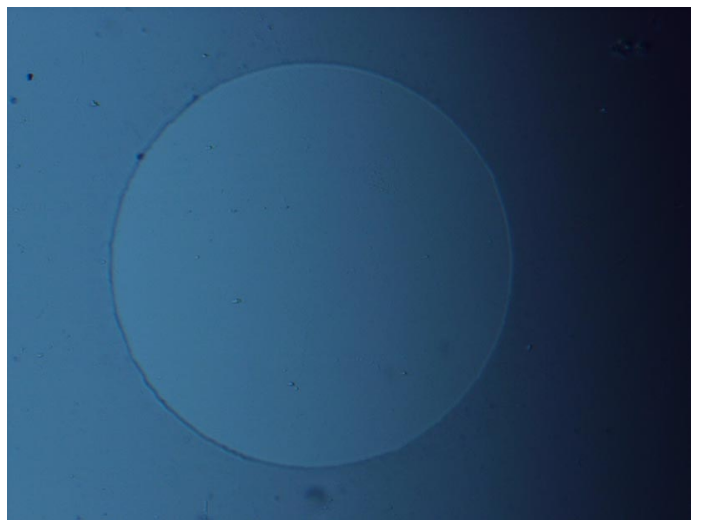

Figure 7.

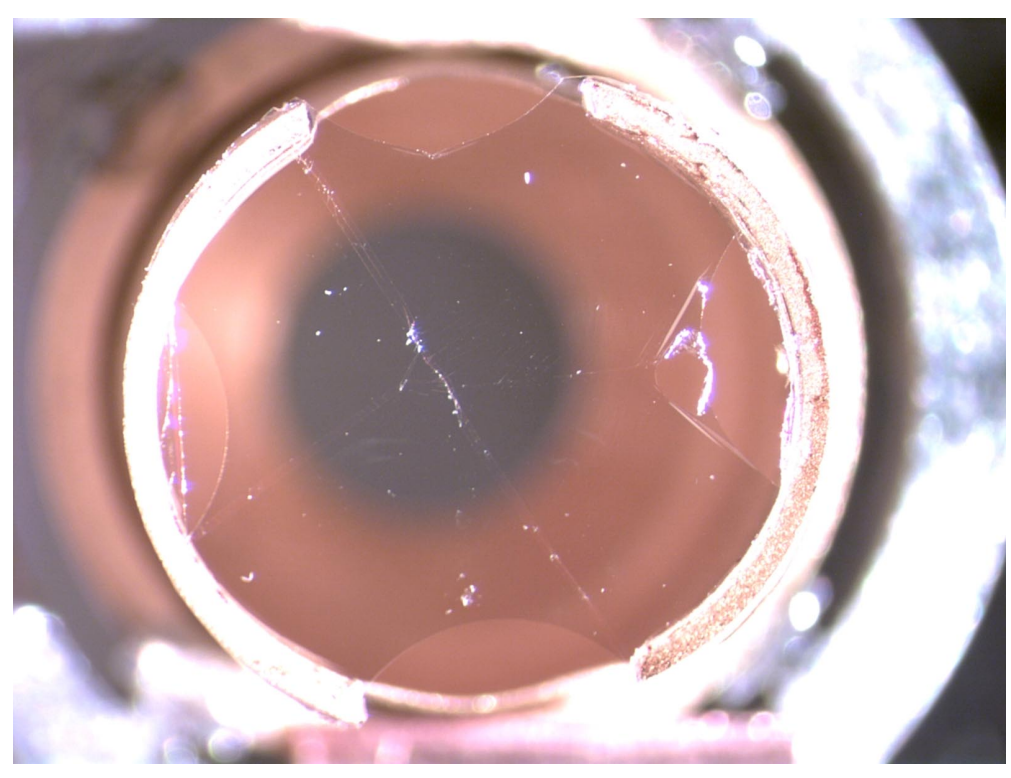

Figure 8. 

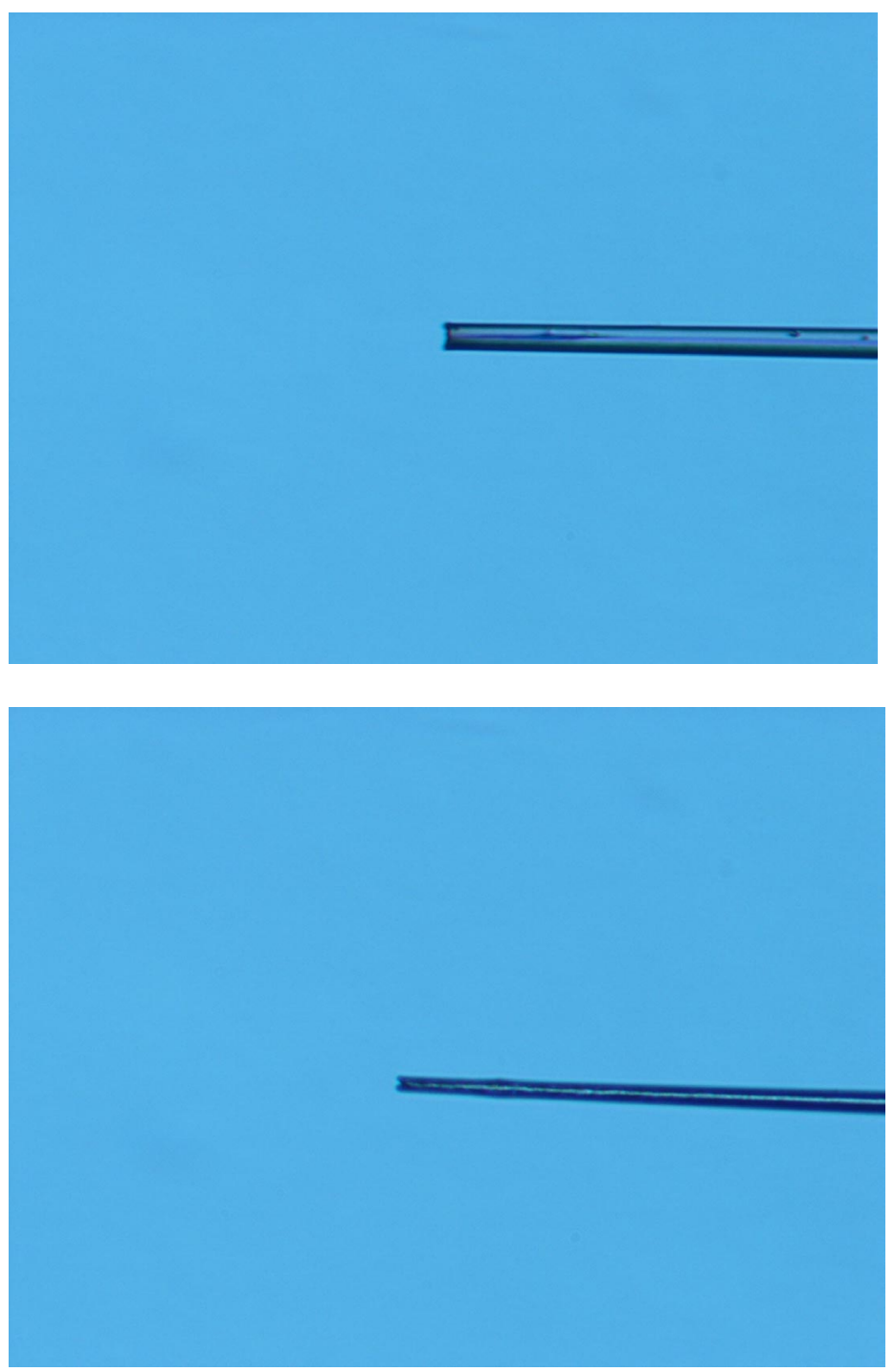

Figure 9. 